\title{
Hospitality spaces, hospitable moments: consumer encounters and affective experiences in commercial settings
}

\author{
Peter Lugosi, PhD \\ School of Services Management \\ Bournemouth University \\ This is the accepted, pre-proof version. The final version was published as: Lugosi, P., 2008. \\ Hospitality Spaces, Hospitable Moments: Consumer Encounters and Affective \\ Experiences in Commercial Settings. Journal of Foodservice, 19 (2), pp. 139-149. DOI: \\ 10.1111/j.1745-4506.2008.00092.x \\ Please consult the final version if citing.
}

\begin{abstract}
This paper examines the production of hospitable experiences within consumer encounters in commercial hospitality spaces. It considers the different dimensions or forms of hospitality and distinguishes between the offer of food, drink, shelter and entertainment within commercial transactions, the offer of hospitality as a means of achieving social or political goals, and meta-hospitality: temporary states of being that are different from rational manifestations of hospitality. It is argued that meta-hospitality is tied to communitesque moments: short-lived emotional bonds that may be built or experienced through hospitality transactions. A case study is used to identify three factors that shape the development of communitesque experiences: the ecology in which it occurs, the participants' roles and their capabilities.
\end{abstract}

Keywords: Hospitality, space, communitas, consumer, experience, emotion

Hospitality spaces, hospitable moments: consumer encounters and affective experiences in commercial settings

\section{Introduction}

There has been growing interest in recent years in the entanglement of social and commercial manifestations of hospitality (Lashley and Morrison 2000; Lugosi 2003, 2007a, 2007b; Molz and Gibson 2007). Academics from a number of disciplines have begun to examine the broader dimensions of hospitality; and in the process they have challenged management oriented research that conceptualises hospitality as a series of organisational functions or service transactions (cf. Lashley et al. 2007). Olesen (1994), King (1995) and Lashley (2000), for example, distinguish between different types of hospitality and examine how socially and culturally defined principles influence its commercial manifestations. Hemmington (2007) draws on these themes and attempts to shift the focus of hospitality research from a narrow set of managerial concerns about service quality and operational efficiency to the social and emotional dimensions of the consumer experience. This emerging body of work has broadened the scope of hospitality research, but these works perpetuate a number of problematic traditions. Firstly, despite recent attempts to examine the emotional aspects of hospitality (e.g. Lashley et al. 2004; Pullman and Gross 2004), the distinction between emotional and functional forms of hospitality has not been considered in detail. Secondly, definitions of 
hospitality provision in commercial contexts continue to focus on a narrow set of transactions - those involving food, drink and the offer of shelter, while largely ignoring issues of entertainment and social intercourse. Finally, contemporary debates about hospitality provision continue to focus on host-guest transactions while neglecting guestguest relations and exchanges (Lashley et al. 2007).

This paper builds on and develops this emerging body of work by distinguishing between the offer of food, drink, shelter and entertainment within commercial transactions, the offer of hospitality as a means of achieving social or political goals, and meta-hospitality: temporary states of mutuality that are different from rational manifestations of hospitality. This distinction is used to understand the ways in which hospitable encounters may be produced and experienced in commercial settings. Furthermore, rather than focusing on the provider-customer or host-guest relationship, the paper examines the relationship between guests or consumers.

The paper begins with a discussion of the constituent parts and the functions and outcomes of hospitality. The following section considers a particular type of relationship that may be formed and transformed through hospitality. The paper draws on Turner's $(1969,1974,1982,1992)$ notion of communitas and proposes an alternative concept, the communitesque. This is subsequently used to conceptualise particular types of hospitable relationships and transactions. Following a short discussion of methods, a case study is used to demonstrate the ways in which such communitesque relationships may be produced and experienced. Finally, the paper identifies the three factors that shape the construction of a hospitable moment: ecology, roles and capabilities.

\section{Forms of hospitality}

Numerous authors attempt to define hospitality and understand it as both social and commercial activity (cf. Brotherton 1999; Brotherton and Wood 2000; Lashley 2000). It is not intention to review the various definitions here; nevertheless, it is important to highlight a dominant theme in accepted definitions. Brotherton (1999: 168) illustrates the point when he defines hospitality as:

A contemporaneous human exchange, which is voluntarily entered into, and designed to enhance the mutual well being of the parties concerned through the provision of accommodation, and/or food, and/or drink.

Brotherton and Wood (2000: 143) subsequently suggest that:

The hospitality industry is comprised of commercial organizations that specialize in providing accommodation and/or, food, and/or drink, through a voluntary human exchange, which is contemporaneous in nature, and undertaken to enhance the mutual well being of the parties involved.

These definitions of hospitality and its commercial provision foreground the provision of food, drink and shelter but play down a further critical dimension of hospitality: 
entertainment and social intercourse. King (1995) identifies a direct relationship between hospitality and entertaining. Drawing on Palmer's (1992) earlier work, King (1995) suggests that throughout history hospitality was inseparably linked with entertainment and entertaining interaction between provider and recipient. Telfer (2000) questions whether hospitality and entertainment are the same things. She states that "hospitality is associated with meeting of needs, entertaining with the giving of pleasure" (2000: 39). Nevertheless, Telfer (2000: 39) claims that this difference is "only a matter of nuance" and uses the word entertaining interchangeably with providing hospitality. However, in considering social manifestations of hospitality in commercial contexts, it is important to treat entertaining social intercourse as a distinct aspect of hospitable transactions.

The provision of hospitality by frontline staff for customers may involve a degree of entertainment, and some foodservice organisations place jocularity and informal interaction at the centre of the service encounter (see Gardner and Wood 1991), but such entertainment is not a necessary part of service provision in the majority of hospitality operations. Nevertheless, within many commercial hospitality environments, guest interaction and entertainment is a fundamental part of the experience, whether it is in the form of passive gazing of the male or female body, convivial interaction or through more outlandish, spectacular identity performances (cf., Lugosi 2003, 2006a, 2007b). Engaging and entertaining interaction often goes hand in hand with the consumption of food and drink (Hanefors and Mossberg 2003). Food, drink and shelter can undoubtedly be offered without entertainment, although the wellbeing of guests as well as customers is often assured because it is part of the experience.

The inclusion of entertainment in a broadened conception of hospitality makes it possible to distinguish between different forms of hospitality transaction and hospitable behaviour. Figure 1 demonstrates the distinction between three manifestations. The first manifestation of hospitality is the provision of food, drink, shelter and entertainment principally as part of a commercial transaction. This is a ubiquitous and often mundane form of hospitality between provider and consumer that fulfils such basic human needs as hunger, thirst and tiredness. Entertainment is usually only included in this type of hospitality transaction when it adds value to the customer experience.

Figure 1 Forms and manifestations of hospitality

[pic]

The second manifestation is the provision of food, drink, shelter and/or entertaining social intercourse for the development of social relationships or the pursuit of political agenda. Selwyn (2000: 19) points to this form when suggesting that hospitality is used "to establish a relationship or to promote an already established relationship...; hospitality converts: strangers into familiars, enemies into friends, friends into better friends, outsiders into insiders, non-kin into kin." Hospitality is conceived as a functional set of activities that have a social or political outcome. It is not suggested that this form of hospitality is always calculated or instrumental; indeed, the nature of the relationship may no longer be purely rational or functional and may have an emotional element.

To some extent at least, the first two manifestations of hospitality can be anticipated, and 
its mundane, functional forms can be managed within the service environment. This is in contrast to the third manifestation: meta-hospitality, which is infrequent, existential in nature and emotional in essence. Those involved in meta-hospitality experiences are less able to anticipate, orchestrate or subsequently recreate them. The notion of metahospitality separates hospitality - as the means to an end - from hospitability or hospitableness as an end itself. Hospitality transactions may fulfil basic physiological, economic, social or political needs, but hospitable interaction is an acknowledgement of the other. Moreover, it is an overt willingness, not only to share one's social space, but to create a shared, experiential space in which the participants become part of a contextually defined social entity. Food, drink, the offer of shelter and entertaining social intercourse form a crucial part of this transaction: they facilitate the relationship and give it an ontological reality, but emotional experience is at the heart of the encounter. Hospitableness is inherently emotional because the hospitable act requires those involved to abandon or suspend rational judgement in the creation of mutual wellbeing and joy. Hospitability is openness towards the other and it is acceptance of the other, albeit temporarily.

Derrida (2000) and Sheringham and Daruwalla (2007) argue that such 'pure' hospitality is unachievable because issues of power and differences in status are so fundamental to the host-guest relations (see also Derrida and Dufourmantelle 2000). Sheringham and Daruwalla (2007) suggest that hospitality may indeed be the creation by the host and guest of a temporary, transgressive, carnivalesque space in which conventional norms are abandoned. However, they also maintain that such carnivalesque experiences serve to reinforce the social order because hospitality is temporary and there are intrinsic limits to its existence. More important, for Sheringham and Daruwalla (2007), hospitality takes place between host and guest, in the host's physical and symbolic space. Hospitality, therefore, serves to release host and guest from existing differences in status, while simultaneously reinforcing differences in status. The stance adopted here is different to this in two ways. First, while differences in status, class, gender etc. are inherently part of a society's practices, i.e., the conditions that determine where and how people interact, hospitableness, as conceived here, is the state of being between social actors where differences are tempered in particular moments. Differences in status, knowledge and competency continue to shape the relationship between individuals, but such differences may no longer be the principal factors that determine the nature of interaction between social actors.

A second and more fundamental difference in this conception of hospitableness is the shift in emphasis from the host-guest/provider-customer to the guest-guest/consumerconsumer transaction in the creation of hospitable space. Because commercial hospitality venues are inhabited by consumers, who may engage with each other as much as they do with the hosts, they create these moments of hospitability between themselves. Consequently, the issues of power and status that are so important in hostguest relations are not the same in guest-guest relations and in their transformation of commercial hospitality venues into hospitable spaces. It is not suggested that hosts or commercial providers do not have a significant role in creating hospitable exchanges. Nor is it assumed that commercial or social providers and consumers engaged in 
mundane forms of hospitality transaction cannot experience meta-hospitality. Nevertheless, this paper focuses on consumers' ability to transform their patronage in commercial hospitality venues into experiences of meta-hospitality.

Hospitability or hospitableness is an emotional and sincere form of engagement; and therefore it is inherently ephemeral. Within hospitable relationships, barriers to interaction produced by differences morality, class and social status become porous, and their influence is tempered in the existential moment. However, these differences in status, background and competence are likely to remerge, and thus limit individuals' ability to interact over extended periods of time. Such an interpretation of hospitality requires an alternative conceptual vocabulary - one drawn from Turner's (1969, 1974, 1982, 1992) work on liminality and communitas. The next section outlines Turner's work and develops his ideas by introducing the notion of communitesque, which is used to understand the experience of meta-hospitality.

\section{Hospitality, hospitability and communitesque experiences}

Two key concepts that help to understand the experience of hospitable moments are liminality and liminoid (Turner 1969, 1974, 1982, 1992). Liminality was originally used in reference to periods of anti-structure experienced in rites of passage ceremonies, during which participants have moved from one structural status, but have not moved to another (cf., Turner 1969; van Gannep 1960). Turner (1969, 1982, 1992) uses the notion of liminality to conceptualise periods of symbolic and emotional detachment from societal norms. He subsequently introduces the concept of the liminoid: anti-structural relations and social phenomena that emerge through contemporary leisure activities. The oid in liminoid is taken from the Greek eidos meaning like or resembling. The liminoid resembles the liminal without being identical to it. Turner (1992: 57) suggests that liminoid phenomena "develop most characteristically outside the central economic and political processes." They are "plural, fragmentary and experimental" and "often subversive, representing radical critiques of the central structures and proposing utopian models."

Central to Turner's notion of liminoid phenomena are the forms of social relationship they engender. Within playful, liminoid leisure activities, participants become members of communitas: social entities temporarily detached from social structures or institutions. Turner (1969, 1974, 1982) goes further and distinguishes between existential, normative and ideological communitas; however, this paper focuses on the notion of existential communitas.

Existential or spontaneous communitas are temporary states of affective bonding created through direct interaction. During these moments participants "become totally absorbed into a single synchronised, fluid event" (Turner 1982: 48), and a sense of "honesty, openness, and lack of pretentions or pretentiousness" is at the heart of the experience. According to Turner (1982: 50-5): 


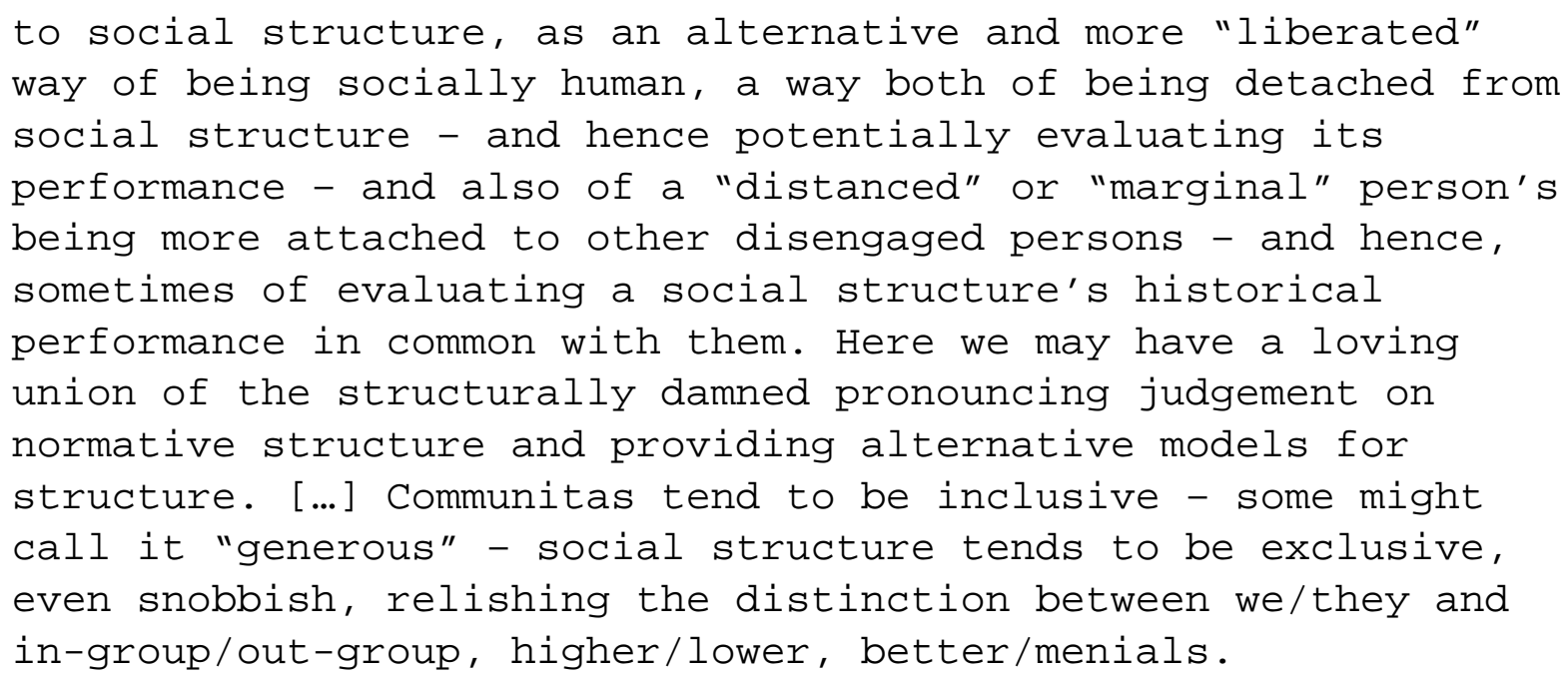

Existential communitas is conceptualised as a psychological construct that is felt or imagined (cf., Turner 1992: 61-65), but the corporeal and physical components of experience have a key role. The experience of communitas may be created through such embodied actions as convivial interaction, mutual entertainment and the physical consumption of food, drinks and shelter. These physical actions also mediate hospitable experiences for other participants. Furthermore, communitas experiences are created through interaction in physical locations and through an interactive relationship between the servicescape and its users, which, as Aubert-Gamet and Cova (1999) argue, may facilitate particular forms of interpersonal and intergroup interaction.

Turner's notions of liminoid phenomena and existential communitas offer a conceptual vocabulary that helps to appreciate both the sense of collective abandonment in hospitable encounters and the short-lived, ephemerality of that engagement. However, an inherent danger in invoking Turner's notion of existential communitas is that it overstates the ecstatic nature of human experience. For example, in discussing existential communitas, Turner (1969: 138) suggests "the often made etymological homology between the nouns "existence" and ecstacy" is pertinent here; to exist is to stand outside" - i.e., to stand outside the totality of structural positions one normally occupies in a social system. To exist is to be in ecstacy." Similarly Myerhoff (1975: 34) states that "by definition, [existential] communitas cannot take place within structure, for it is ecstatic, literally an escape from the self. The spirit, in soaring flight, is liberated from the body and, correspondingly, from social and historical rootedness that provides the daily mortal context." Myerhoff (1975) maintains that existential communitas may be planned and organised, but they are, by their very nature, not routinized or mundane. Existential communitas is an evocative term that makes direct reference to the emotional dimensions of interaction and the sense of liberated abandonment it entails; however, to understand meta-hospitality it is necessary to temper the concept.

An alternative term proposed here is the notion of communitesque experiences. The suffix esque implies that it may contain traces of existential abandonment, but is more sober and draws on a series of social and cultural competencies that allow individuals to interact. Whereas communitas "ignore, reverse, cut across, or occur outside of structural 
relationships" (Turner 1974: 274), communitesque experiences may challenge, soften, negotiate and disrupt socially constructed statuses without completely abandoning them. A communitesque experience involves a temporary sense of unity or sociality between individuals. As with existential communitas, communitesque experiences are fundamentally psychological constructs; they are sensed and they are felt.

Communitesque moments are synonymous with meta-hospitality because it is more than the mere exchange of food or drinks, or offers of shelter. Rather, the offers of food, drink and shelter and the acts of mutual entertainment between social actors are prosthetics material and embodied mediators - that enable individuals to experience the communitesque.

Communitesque experiences are lived and are created through close interaction in particular spaces and times. Communitesque encounters are not ecstatic, liminal periods of abandonment: they are liminoid experiences in which the rationality of relationships is abandoned in favour of a playful, emotional openness towards one another. These experiences involve the production and consumption of food, drink and the offer of shelter, but they are fundamentally about the creation of a shared emotional space.

\section{Methods}

The empirical case used to develop the notion of meta-hospitality is drawn from a larger ethnographic study of the relationship between hospitality and space (see Lugosi 2003, 2006b). This case was identified through exploratory fieldwork which utilised an opportunistic or emergent sampling strategy (Patton 2002). Data were collected through participant observation during a visit to a commercial hospitality venue and the incident which took place in this context was used to develop an emergent conceptual theme. The researcher primarily adopted an observer role, although the nature of the context made it difficult to disentangle observation from participation. Lugosi (2003) argues that co-presence and the act of informal but overt observation in a commercial hospitality venue becomes a form of participation in the creation of social events. However, rather than treating this as a weakness, Patton (2002) suggests that being part of social processes provides useful insights into the forces that help to produce them.

Following the visit to the venue a "thick description" (Geertz 1973) of the incident was written, which sought to provide details of the context and the minute factors that contributed to the event that took place. Denzin (1989: 83-4) argues that such "thick description creates verisimilitude; that is, truthlike statements that produce for the readers the feeling that they have experienced, or could experience, the event, being described." The description of the incident included elements what Denzin (1989: 91-92, 93-5) defined as micro, situational and interactional description. More specifically, the account focuses on a specific micro context and considers the location, including the physical qualities of the venue, and the interactions of those present at the time. This account was subsequently interrogated to identify emerging conceptual themes.

\section{The case study: Hospitality space, hospitable moment}


12.15 a.m., Budapest, Hungary

Walking down Nagymez? Utca it was easy to miss the place: there were no windows and the entrance was a small black door. A small neon sign above the door said 'Piaf' [after the French singer Edith Piaf].

We rang the bell and an assertive blond-haired woman opened the door. She told us sternly that it cost 500 Forints to come in and that this was a 'private bar'. [Prior to our visit, others had told us about the entrance ritual. Just like a scripted greeting at a quick-service restaurant, the welcome was exactly as people had described it, down to the colour of her hair and her attitude.] We paid the money and stepped into a small, dark, smoke-filled room, painted with deep red and black colours. The lighting was low and candles were burning on the tables.

There was a bar on the right side of the room and sets of low tables and chairs closely pushed together in between the bar and the door. A similar row of tables and chairs were set against the left-hand side of the room. A narrow space between the tables on the left and the bar on the right led through to the back of the bar. A piano was squeezed into the right-hand corner facing the bar with a number of chairs and settees around it.

We sat down at one of the tables in front of the piano. Two women in their mid 20s were sitting to the left of us. An older man was playing the piano, while a woman in her late 40s sang French chanson songs. After about half an hour, the singer finished her set and the man continued to play the piano. The proximity of the tables to the piano meant all the patrons at the tables could talk to the pianist. One of the two women asked for some songs. The pianist produced a songbook and she stood up and looked through it. Meanwhile, four men had sat down at the table next to the piano. Three casually dressed, all in their late 20 s or early 30 s. The fourth was considerably better dressed and obviously thought highly of himself.

While looking through the songbook, the woman asked about certain songs and the pianist played the first few notes from each song. After a while, the woman started to sing some of the songs she recognised, but in a quiet voice. She constantly looked up at her friend who was watching and encouraging her, showing obvious amusement and giving supportive comments. Having agreed on a song, the pianist played it and she sang it all the way through, albeit quietly and nervously. We all clapped, including the four men sitting next to the piano who had also taken an interest in her performance.

The woman and the pianist decided to try another song and one of the four men stood up and started to look through the songbook. The pianist, the woman and the 
man agreed on a new song and sang it. By this time, the friend of the woman had moved next to the piano alongside the other men. They sang another song, and everyone, including us, seemed to find it very amusing. More people started clapping, including another two inebriated men, who, until then, had been having a loud conversation at a table just to the right of us. Alongside clapping, one of the men started making a clicking noise with his mouth.

Two more men (both in their mid to late 20s) came from one of the back tables and joined in. The newcomers and the three still-seated men offered suggestions. Most of these were Hungarian quasi-folk songs from the 1970s onwards. The singing got louder and the woman who instigated the performance started to sing with more confidence. All the men seated at the front were singing by now, except for the welldressed man who seemed to be above such behaviour. Another older man (late 40s) came over from the back of the bar and joined in the impromptu concert. They were all singing loudly, and in unison, while visibly enjoying themselves and constantly exchanging smiles and comments. This went on for approximately 15 minutes, after which time they seemed to lose enthusiasm: several of the men stopped singing and the singing became quieter and less coordinated among those who continued. Eventually, the two men returned to their tables at the back of the bar and the woman sat down with her friend next to the four men seated near the piano. The older man stayed near the piano where he had been singing. He looked uncomfortable and shuffled about on the spot while continuously taking sips from his drink. After a few minutes he also went back to his table at the back of the bar. The two women and the four men continued drinking and talking for several more minutes, but the two groups eventually turned to their separate conversations. One of the two drunken men to the right of us kept clapping and making noises after the others stopped singing. This noise was audible throughout the bar and the assertive, blonde-haired woman went up to him after a while and asked if he was O.K., which effectively meant 'stop doing that'.

\section{Discussion}

The participants did not appear to know each other prior to that night. This was certainly true for the two women and the four men, who did not acknowledge each other when the men sat down. This also seemed to be the case for the two young men and the older man who came from the back of the bar. They did not engage in lengthy greetings when they joined the people singing and they went back to their tables as soon as the singing ended rather than staying to communicate. Nevertheless, the "focused activity" (Goffman 1963) of singing was a point of commonality, and those participating transformed the mundane service space into a hospitable space. It is important to emphasise the temporal element of the incident. Participants briefly found novelty, amusement and a sense of commonality, but the social unit was the strongest and most coherent during a very short period. Some of those present were more enthusiastic and came into closer physical and social proximity during the hospitable moment, although others (i.e., the welldressed, self-conscious man) remained more detached. The incident highlights the 
ephemeral, liminoid nature of the communitesque moment. The sense of commonality was quickly exhausted and existing divisions between individuals remerged. For example, none of those present engaged the older man in conversation. The two women talked briefly with the other men, but the women turned away from them after a few minutes and resumed talking to each other. Once the moment had passed, general rules of conduct and decorum were reclaimed by most of the participants. The heavily inebriated man failed to acknowledge this and kept making a disruptive noise after the singing had finished. He was subsequently reprimanded.

There are unique features of the Piaf incident; nevertheless, it is possible to speculate about the necessary factors that underpin the emergence of meta-hospitality. The final section identifies and discusses three factors that shaped the creation of this communitesque moment: ecology, roles and capability.

\section{Ecology}

The relationship between the service environment and consumer experiences has long been recognized (Pullman and Gross (2004). The semiotic qualities of hospitality spaces shape the actions and perceptions of hosts and guests, or service providers and their consumers (e.g., Lugosi 2003; Cuthill 2007; Di Domenico and Lynch 2007). Carbone and Haeckel (1994), Berry et al. (2002) and Berry and Bendapudi (2003) suggest that operators can purposefully design and manipulate the service environment to guide customer perceptions and experiences. Within the case study site the physical environment undoubtedly played an important role: the furnishings and layout of the bar forced customers closer together, which increased the likelihood of interaction. Therefore it is possible to conclude that communitesque experiences may require a physical layout that encourages close physical proximity and inter-group rather than intra-group interaction. However, the layout or furnishings of the service environment alone cannot guarantee interaction among guests. It is important to remain critical of the assumption that service providers can simply orchestrate consumer experiences. Prahalad and Ramaswamy (2004) argue that positive consumer experiences are often dependent on customers' active participation in the creative process. Consequently, consumers' ability to investigate, occupy, delineate and subvert space may determine whether communitesque experiences emerge.

Roles

A number of individuals played a prominent role in creating the experience. The communitesque moment was instigated by the woman who initially stood up, selected the music and decided to start the singing after the professional singer withdrew. This became the focal point of activity. The pianist had a crucial facilitating role in encouraging people to suggest songs; as did the staff who allowed the events to unfold uninterrupted. The man who initially stood up and joined in accelerated and intensified the activity; so did the signing woman's friend by moving closer to the piano. However, everyone in the vicinity played an active part both in intensifying and directing the activities. Watching, laughing and clapping encouraged the playful sentiment. Furthermore, the suggestion of songs by those seated and standing directed the nature of the encounter and the participants' actions. 
Previous research demonstrates that staff and consumers have roles in creating service encounters, consumer experiences (McGrath and Otnes 1995; Price et al. 1995; Carù and Cova 2006) and in producing hospitality spaces (Katovich and Reese 1993; Lugosi $2003,2006 a)$. The case study highlights several specific roles that may be necessary for the creation of communitesque experiences. These include: a) instigator, who initiates the focused activity that becomes the basis of association; b) accelerator or enhancer, who intensifies the interaction and thus reinforces its significance; c) director, who shapes the patterns of the interaction and the direction in which it develops; and d) facilitator, who plays passive or active roles in the development of the encounter. This facilitation may include the provision of the context, meditation between those involved or non-interference. Certain patrons in the case study had more distinct roles within the encounter; however, the incident also demonstrates that individuals can simultaneously perform one, more or all of these roles.

The performance of roles in this type of hospitable encounter relies on a series of socially or culturally determined competencies; nevertheless, it is important to emphasise the emerging nature of these roles. Moisio and Arnould (2005) highlight the dynamic relationship between roles shaped by a series of organisational and cultural forces and those constructed through the consumption process. Some roles, for example, those performed by frontline service staff may be shaped more directly by organisational policies and norms. Consumers' roles are less predictable, and their actions reflect the disruptive and creative qualities of meta-hospitality and communitesque experiences.

\section{Capability}

Consumer's ability to interact and to create meaningful experiences is dependent on their knowledge, skills and competencies. Chervonnaya (2003) suggests that the three concepts are interrelated but refer to different aspects of consumer behaviour. Following a review of the literature, Chervonnaya (2003: 354) concludes that "for Senker (1995) ... knowledge implies "understanding", whereas skill means "knowing how to make something happen". Competence, in turn, differs from skill in that it requires "the use of situationspecific information", whereas skills do not (Kirschner et al. 1997, p. 155)." Capability is deliberately used in this paper because it incorporates all three of these concepts. Capabilities in the Piaf case refer in part to the knowledge of Hungarian songs, which is a form of cultural capital (Bourdieu 1986) that participants could mobilise. Participants' interpersonal and communicational skills, including the ability to sing, were also capabilities that allowed meta-hospitality to emerge. Other contexts and communitesque moments will depend on a different set of capabilities. Nevertheless, the creation of hospitable moments is likely to be underpinned by participants' ability to mobilise capabilities developed outside and inside the service environment.

\section{Conclusion}

This paper has distinguished between mundane transactions of food, drink, shelter and social intercourse, hospitality mobilized for social or political purposes, and meta- 
hospitality: short-lived, emotional states of being when participants create a shared existential space in which differences are temporarily re-negotiated or tempered.

Developing Turner's $(1969,1982)$ notion of communitas, the paper introduced the notion of communitesque to conceptualise the experiences that emerge within hospitable moments. The case study was used to identify several important conditions and factors that may enable meta-hospitality and communitesque experiences to materialise. It pointed the role of the ecology in shaping consumer interactions; it illustrated the importance of human agency and the roles that individuals may assume in transforming those ecologies; and it also demonstrated that numerous capabilities may be required for the creation of hospitable transactions.

Meta-hospitality and communitesque experiences are not inevitable cathartic eventualities within any hospitality transaction. Nevertheless, the notion of communitesque experiences offers a conceptual tool with which to understand emotionally driven hospitable interactions. Distinguishing between the functional and emotional aspects of hospitality helps to develop a more nuanced understanding of its different forms. Moreover, it also helps to shift the focus of inquiry from providercustomer to consumer-consumer interactions. Frontline staff and customers inevitably engage in service relationships in most commercial hospitality spaces. However, hospitality cannot always be reduced to these types of exchanges. Functional providercustomers transactions may form only one part of the overall consumer experience. Staffcustomer relations may be transformed into hospitable exchanges; and, as the case illustrates, interactions between consumers can fundamentally transform the nature of the consumption experience. Commercial operators may provide the context for functional hospitality transactions and the creation of hospitable relationships; they may also have a significant role in facilitating and helping to orchestrate consumers' experiences. However, the provision of such contexts and services represents a series of possibilities; and it is in the social encounter, sometimes between provider and customer, but often, between consumers themselves, that hospitable spaces are brought to life.

\section{References}

Aubert-Gamet V, Cova B (1999). Servicescapes: From modern nonplaces to postmodern common places. Journal of Business Research $41(1): 37-45$.

Berry L, Bendapudi N (2003). Clueing in the customers. Harvard Business Review 81(2): 100-106.

Berry L, Carbone L, Haeckel S (2002). Managing the total customer experience. MIT Sloan Management Review 43(3): 85-89.

Bourdieu P (1986). The forms of capital. In: Handbook of Theory and Research for the Sociology of Education (ed. JG Richardson), pp. 241-258. Greenwood Press: New York.

Brotherton B (1999). Towards a definitive view of the nature of hospitality and hospitality 
management. International Journal of Contemporary Hospitality Management 11(4): 165173.

Brotherton B, Wood RC (2000). Hospitality and hospitality management. In: In Search of Hospitality: Theoretical Perspectives and Debates (eds. C Lashley, A Morrison), pp. 134156. Butterworth-Heinemann: Oxford.

Carbone L, Haeckel S (1994). Engineering customer experience. Marketing Management 3(3): 8-19.

Carù $A$, Cova $B$ (2006). How to facilitate immersion in a consumption experience:

Appropriation operations and service elements. Journal of Consumer Behaviour 5: 4-14.

Chervonnaya O (2003). Customer role and skill trajectories in services. International Journal of Service Industry Management 14(3): 347-363.

Cuthill V (2007). Sensing and performing hospitalities and socialities of tourist places: Eating and drinking out in Harrogate and Whitehaven. In: Mobilizing Hospitality: The Ethics of Social Relations in a Mobile World (eds JG Molz, S Gibson), pp. 83-100. Ashgate: Aldershot.

Denzin NK (1989). Interpretative Interactionism. Sage: Newbury Park, CA.

Derrida J (2000). Hostipitality. Angelaki: Journal of Theoretical Humanities 5(3): 3-18.

Derrida J, Dufourmantelle A (2000). Of Hospitality. Stanford University Press Stanford.

Di Domenico M, Lynch P (2007). Commercial home enterprises: Identity, home and setting. In: Hospitality: A Social Lens (eds C Lashley, P Lynch, A Morrison), pp. 117-128. Elsevier: Oxford.

Gardner K, Wood RC (1991). Theatricality in food service work. International Journal of Hospitality Management 10: 267-278.

Geertz C (1973). The Interpretation of Cultures. Basic Books: New York.

Goffman E (1963). Behavior in Public Places: Notes on the Social Organization of Gatherings. Free Press: New York.

Hanefors M, Mossberg L (2003). Searching for the extraordinary meal experience. Journal of Business and Management 9(3): 249-270.

Hemmington $N$ (2007). From service to experience: Understanding and defining the hospitality business. The Service Industries Journal 27 : 747-755.

Katovich M, Reese W (1987). The Regular: Full-time identities and membership in an 
urban bar. Journal of Contemporary Ethnography 16(3): 308-343.

King CA (1995). What is hospitality?. International Journal of Hospitality Management 14(3/4): 219-234.

Kirschner P, Van Vilsteren P, Hummel H, Wigman M (1997). The design of a study environment for acquiring academic and professional competence. Studies in Higher Education 22(2): 151171.

Lashley C (2000). Towards a theoretical understanding. In: In Search of Hospitality: Theoretical Perspectives and Debates (eds C Lashley, A Morrison), pp. 1-17. ButterworthHeinemann: Oxford.

Lashley C, Morrison A (2000). (eds) In Search of Hospitality: Theoretical Perspectives and Debates. Butterworth-Heinemann: Oxford.

Lashley C, Morrison A, Randall S (2004). My most memorable meal ever! Hospitality as an emotional experience. In: Culinary Taste (ed. D Sloan), pp. 165-184. Elsevier: Oxford.

Lashley C, Lynch P, Morrison A (2007). (eds) Hospitality: A Social Lens. Elsevier: Oxford.

Lugosi P (2003). The production and consumption of hospitality space. Unpublished doctoral dissertation, University of North London.

Lugosi P (2006a). Working (the) patrons: An ethnographic study of consumer participation in the licensed sector. In: The Proceedings of the $15^{\text {th }}$ CHME Research Conference (eds C Lashley, W Best), pp. 222-232. Centre for Leisure Retailing, Nottingham Trent University: Nottingham.

Lugosi P (2006b). Between overt and covert research: Concealment and revelation in an ethnographic study of commercial hospitality. Qualitative Inquiry 12(3): 541-561.

Lugosi P (2007a). Queer consumption and commercial hospitality: Communitas, myths, and the production of liminoid space. International Journal of Sociology and Social Policy 27(3/4): 163-174.

Lugosi P (2007b). Consumer participation in commercial hospitality. International Journal of Culture, Tourism and Hospitality Research 1(3): 227-236.

McGrath MA, Otnes C (1995). Unacquainted influencers: When strangers interact in the retail setting. Journal of Business Research 32: 261-72.

Moisio R, Arnould EJ (2005). Extending the dramaturgical framework in marketing: 
Drama structure, drama interaction and drama content in shopping experiences. Journal of Consumer Behaviour 4(4): 246-256.

Molz JG, Gibson S (2007) (eds) Mobilizing Hospitality: The Ethics of Social Relations in a Mobile World. Ashgate: Aldershot.

Myerhoff BG (1975). Organization and ecstasy: Deliberate and accidental communitas among Huichol Indians and Amercian youth. In: Symbol and Politics in Communal Ideology: Cases and Questions (eds SF Moore, BG Myerhoff), pp. 33-67. Cornell University Press: London.

Olesen V (1994). Selves and a changing social form: Notes on three types of hospitality. Symbolic Interaction 17(2): 187-202.

Palmer DW (1992). Hospitable Performances: Dramatic Genre and Cultural Practices in Early Modern England. Purdue University Press: West Lafayette, IN.

Patton MQ (2002). Qualitative Research and Evaluation Methods, 3rd edn. Sage: Newbury Park, CA.

Prahalad CK, Ramaswamy V (2004). Co-creation experiences: The next practice in value creation. Journal of Interactive Marketing 18(3), 5-14

Price LL, Arnould EJ, Tierney P (1995). Going to extremes: Managing service encounters and assessing provider performance. Journal of Marketing 59: 83-97.

Pullman ME, Gross MA (2004). Ability of experience design elements to elicit emotions and loyalty behaviors. Decision Science 35(3): 551-578.

Senker J (1995). Tacit knowledge and models of innovation. Industrial and Corporate Change 4: 425-47.

Selwyn T (2000). An anthropology of hospitality. In: In Search of Hospitality: Theoretical Perspectives and Debates (eds C Lashley, A Morrison), pp. 18-37. ButterworthHeinemann: Oxford.

Sherringham C, Daruwalla P (2007). Transgressing hospitality: Polarities and disordered relationships? In: Hospitality: A Social Lens (eds C Lashley, P Lynch \& A Morrison), pp 33-45. Elsevier: Oxford.

Telfer, E. (2000). The philosophy of hospitableness. In: In Search of Hospitality: Theoretical Perspectives and Debates (eds C Lashley \& A Morrison), pp 38-55. Butterworth-Heinemann: Oxford.

Turner V (1969). The Ritual Process: Structure and Anti-structure. Aldine: Chicago. 
Turner V (1974). Dramas Fields and Metaphors: Symbolic Action in Human Society. Cornell University Press: Ithaca, NY.

Turner V (1982). From Ritual to Theatre: The Human Seriousness of Play. PAJ Publications: New York.

Turner V (1992). Blazing the Trail: Way Marks in the Exploration of Symbols. University of Arizona Press: Tucson, AZ.

van Gannep A (1960). The Rites of Passage. Routledge and Kegan Paul: London.

Existential and discontinuous

Nature of experience and pattern of occurrence

Purposeful and mobilised only for social investment

Mundane and ubiquitous; meeting basic human needs

The offer of food, drink, shelter and entertainment for social or political purposes

The offer of food, drink and shelter and entertainment (most often within a commercial transaction)

Emotional transaction

Instrumental

transaction

\&'(@Imnosz€" $\mu[?] \quad$, $\quad$ M Meta-hospitality 